\title{
Histomorphological and Immunophenotypic Characterization of Feline Injection Site-Associated Sarcoma
}

\author{
Sílvia Teixeira Pereira', Conrado Oliveira Gamba ${ }^{2}$, Rodrigo Santos Horta ${ }^{3}$, Rúbia Monteiro de Castro Cunha ${ }^{3}$, \\ Gleidice Eunice Lavalle ${ }^{3}$, Geovanni Dantas Cassali ${ }^{4} \&$ Roberto Baracat de Araújo $^{3}$
}

\begin{abstract}
Background: Feline Injection Site-Associated Sarcoma (FISS) is a mesenchymal neoplasia of aggressive behavior that develops in sites where vaccine or drugs were administered. FISS is clinically characterized by the appearance of a solitary firm nodule or a diffuse mass, adhered to tissues, in regions associated to vaccine or drug applications. Despite low prevalence, tumor recurrence rates can reach $80 \%$. FISS present more aggressive histological characteristics when compared to sarcomas not associated to injection sites. The aim of this paper is to contribute towards the understanding of the biological behavior of FISS.
\end{abstract}

Materials, Methods \& Results: Sixteen samples of FISS were analyzed. Fibrosarcomas were the most frequent histological subtype (62.5\%). Malignant peripheral nerve sheath tumor was diagnosed in $18.75 \%$ cases. Ten $(62.5 \%)$ FISS were classified as grade II; 4/16 (25\%) grade I, and 2/16 (12.5\%) grade III. Cox-2 overexpression occurred in 3/16 (18.75\%) samples, with positive correlation between Cox-2 expression and cellularity $(\mathrm{r}=0.696, P=0.003)$. Mitotic index lower than 9 events was found in 11/16 (68.7\%) samples and between 10 and 19 mitotic events in 5/16 (31.3\%) cases. Mean Ki-67 expression was $2.39 \pm 2.48 \%$. FISS characterized as fibrosarcomas presented longer overall survival (median 545 days) than other histological subtypes (median 130.5 days) $[P=0.01]$.

Discussion: Patients with FISS generally present with larger nodules than those with sarcomas not associated to injections, suggesting a challenge for pet owners to note subcutaneous tumors in the interscapular region, in addition to the aggressive biological behavior of FISS. The influence of size on prognosis remains controversial. An association between histologic grade and the development of metastasis has been observed, with patients with grade III FISS associated with an increase in the metastatic rate. The present study did not find a correlation between overall survival and histologic grade. A positive correlation between the presence of giant multinucleated cells and tumor grade has been observed. Despite the absence of such correlation in the present study, possibly due to a small sample, a trend for higher frequency of giant cells in advanced histologic grade was observed. Cox-2 expression in $81.75 \%$ and overexpression in $18.75 \%$ of our samples contrasts with the $64 \%$ Cox- 2 expression and the absence of Cox- 2 expression found by other authors. A positive moderate correlation between cellularity and Cox-2 expression was also observed, while another study did not find a correlation of Cox-2 expression with tumor grade, recurrence rates or overall survival. Cox metabolites such as prostaglandins can enhance cellular proliferation, inhibit apoptosis, induce angiogenesis, alter cellular adherence to facilitate metastatic development and inhibit immune surveillance. In the present study, no correlation was found between Cox-2 and angiogenesis in FISS. Our findings demonstrated low immunolabeling for Ki-67. A previous study analyzed 52 samples of FISS, 51\% of them considered grade III, with a mean Ki-67 labeling of 14\%. The lower Ki-67 staining in the samples of the present study may be related to the lower number of samples of grade III FISS or to a difference in the studied population. Fibrosarcomas are associated with better prognosis than other histological subtypes. Furthermore, malignant peripheral nerve sheath tumors were diagnosed as a possible histological subtype of FISS.

Keywords: fibrosarcoma, cyclooxygenase 2, Ki-67, neoplasm, FISS. 


\section{INTRODUCTION}

Since 1990, veterinarians noticed an increase in frequency of cutaneous and subcutaneous fibrosarcomas in dorsal, cervical and interscapular region of felines, regions generally used for vaccines and drug applications [16]. These cases were subsequently denominated Feline Injection Site-Associated Sarcomas (FISS) and are clinically characterized by the appearance of a solitary firm nodule or a diffuse mass, adhered to tissues, in regions associated to vaccine or drug applications [27]. Time of tumor development following vaccination varies from four months to 10 years [2]. The estimated occurrence of FISS is between $0.36 / 10000$ vaccinations [12] to $1 / 1000$ vaccinations $[18,26]$.

FISS present more aggressive histological characteristics when compared to sarcomas not associated to injection sites, revealing intense cellular and nuclear pleomorphism, wide areas of necrosis and high mitotic activity. Moreover, occurrence of a peripheral inflammatory infiltrate, composed mainly of lymphocytes and macrophages is common $[8,15]$.

The oncogenic pathways that originate FISS have been described as different from other sarcomas, constituting a distinct pathological entity $[8,18,23]$. Persistent lymphocytic inflammation and the proliferation of fibroblasts and myofibroblasts associated to the inflammatory reaction combined with the activation of oncogenes and/or inactivation of tumor suppressor genes are suggested as possible causes for the development of FISS [18,30].

The goal of this study was to contribute towards the understanding of FISS biological behavior through the evaluation of histopathological and immunohistochemical (Cox-2, Ki-67 expression) characteristics and survival rates.

\section{MATERIALS AND METHODS}

\section{Sample collection}

Paraffin blocks containing feline sarcomas from 2001 to 2013 were obtained from the Pathology Department of the Veterinary School and from the Laboratory of Comparative Pathology of the Federal University of Minas Gerais (UFMG). Samples of tumors surgically excised from regions commonly used for subcutaneous injections (thoracic dorsal and costal region, flank, and limbs) or presenting clinical history of prior application at the nodule site were selected. Information regarding breed, age, sex, size of the tumor, treatments performed, and clinical evolution were obtained from patient medical records and pet owner interviews.

\section{Histopathology}

To establish a histopathological diagnosis, $4 \mu \mathrm{m}$ sections were obtained from paraffin blocks and stained with hematoxylin and eosin (HE) [17]. Complementary diagnostic tests with immunohistochemistry with vimentin [Vimentin Monoclonal Antibody (SP20)] ${ }^{1}$, S100 [S-100 beta Monoclonal Antibody (SH-B1) $]^{1}$ or special staining with safranin (Safranina $\mathrm{O})^{2}$ were used when histopathology was insufficient to accurately diagnose the neoplasm. Tumor cellularity (low, moderate, or high), giant cell presence, and presence of inflammatory infiltrate were evaluated. Inflammatory infiltrate was classified according to the predominant cellular type (lymphocytic, lymphoplasmacytic), distribution (score 1 = focal; score 2 = multifocal; score 3 = diffuse), and intensity ( score 1 = low; score 2 = moderate; score $3=$ high). The product obtained by multiplication of distribution and intensity scores allowed the definition of a 1 to 9 magnitude scale of peritumoral inflammation. Formation of lymphoid follicles amid inflammatory infiltrate was also registered.

Histological grade of FISS was defined through evaluation of histological differentiation, tissue necrosis and mitotic count, described in Table 1. Tumor scores were added and classified as: grade I / low grade: 3 - 4 points; grade II / intermediate grade: $5-6$ points; and grade III / high grade: 7 - 9 points [5].

Table 1. Scoring system for feline injection site sarcoma histological grade.

\begin{tabular}{ll}
\hline Parameter & Points \\
\hline Differentiation & \\
Resembling adult mesenchimal tissue & 1 \\
$\quad$ Specific histological subtype & 2 \\
$\quad$ Nondifferentiated & 3 \\
\hline Necrosis & \\
Absent & 1 \\
$<50 \%$ & 2 \\
$\geq 50 \%$ & 3 \\
\hline
\end{tabular}

Mitotic count*

$0-9$

$10-19$

$\geq 20$

2

*The mitotic count was done in selected fields of the periphery of the tumor, by two observers, with 10x ocular and 40x objective-glass, counted in 10 high power fields. 
Microvascular density, collagen production, and confirmation of fibroblastic histogenesis of the tumor were evaluated through Gomori Trichrome stain. Microvascular density was determined by counting intratumoral neovessel in ten 400x magnification hot spots, followed by the determination of medium vascular index. Vessels were defined as a group of endothelial cells with lumen containing red blood cells in the center. Vessels presenting muscular layer were not considered.

\section{Immunohistochemistry}

For immunohistochemistry analysis, $4 \mu \mathrm{m}$ histological sections were used, and details are described in Table 2 . Endogenous peroxidase activity was blocked with a solution of $3 \% \mathrm{H}_{2} \mathrm{O}_{2}$ in methyl alcohol. Immunohistochemical procedures were identified with a polymerized secondary antibody (Advance HRP®) ${ }^{3}$. Reagents were applied manually, and immunoreactivity was visualized by slide incubation for $10 \mathrm{~min}$ in diaminobenzidine (DAB substrate system $\left.{ }^{\circledR}\right)^{3}$. Samples of neoplasia previously tested for Ki-67 [ki-67 Monoclonal Antibody (SolA15), eBioscience $\left.{ }^{\circledR}\right]^{1}$ and sections of a canine kidney, known for Cox-2 positivity, were used as positive control. Negative control was obtained by substitution of the primary antibody for regular serum (Ultra V Block®) ${ }^{1}$.
Proliferation index was calculated through the number of positive nuclei for Ki-67 in a total of 1000 neoplastic cells in hot spots [9]. Positivity for Cox-2 was demonstrated by presence of cytoplasmic marking, evaluated semi quantitatively, with a distribution score defined by the percentage of positive cells in five 400x magnification fields. It was classified as: 0 absence of staining; 1 - less than $10 \%$ of stained cells; 2 - 10-50\%; 3 - 31-90\%; and 4 - more than 90\%. Immunohistochemical scores of 3 and 4 ( $\geq 50 \%$ positive cells) indicated Cox-2 overexpression [14].

\section{Statistical analysis}

Spearman's correlation test was used to access the association between the different studied variables. Statistically significant correlations $(P<0.05)$ were considered strong when they occurred in more than $49 \%$ of the studied population $(\mathrm{r}>0.07)$, moderate, when they occurred in 9 to $49 \%(0.3<\mathrm{r}<0.7)$, and weak, when they occurred in less than $9 \%$ of the population $(r<0.3)$. Overall survival and disease-free survival rates were evaluated in univariate analysis derived from the Kaplan-Meier estimate and compared by the long-rank test. Values were considered statistically significant when $P<0.05$.

Table 2. Immunohistochemical antibodies, clones, sources, dilutions, antigen retrieval method and incubation in patients with feline injection site sarcoma.

\begin{tabular}{ccccc}
\hline $\begin{array}{c}\text { Antibody } \\
(\text { Clone })\end{array}$ & Source & Dilution & $\begin{array}{c}\text { Antigenic recuperation } \\
{\left[\text { temperature }\left({ }^{\circ} \mathrm{C}\right) / \text { exposure time }(\mathrm{min})\right]}\end{array}$ & $\begin{array}{c}\text { Incubation Time }(\mathrm{h}) / \\
\text { Temperature }\end{array}$ \\
\hline $\begin{array}{c}\text { Ki-67 } \\
(\mathrm{MIB}-1)\end{array}$ & Dakocytomation & $1: 25$ & $\begin{array}{c}\text { Pressurized heat } \\
(125 / 2) \text { with citrate buffer } \mathrm{pH} 6.0^{*}\end{array}$ & $16 / 4^{\circ} \mathrm{C}$ \\
$\begin{array}{c}\text { Cox-2 } \\
(\mathrm{SP} 21)\end{array}$ & Neomarkers & $1: 80$ & Water bath $(98 / 20)$ with citrate buffer $\mathrm{pH} 6.0^{*}$ & 1/room temperature \\
\hline
\end{tabular}

*Dakocytomation target retrieval solution.

\section{RESULTS}

\section{Histopathology and immunohistochemistry}

Sixteen cases of FISS were evaluated. Mean tumor size following surgical excision was $4.26 \pm 3.19 \mathrm{~cm}$ (range 0.5 to $10 \mathrm{~cm}$ ). Six (40\%) neoplasms were found in the thoracic dorsal region, $5 / 15(33 \%)$ in the flank, $3 / 15$ $(20 \%)$ in the costal region, and $1 / 15(7 \%)$ in a thoracic limb.

Fibrosarcoma was the most prevalent histological type, occurring in 10/16 (62.5\%) of cases, followed by $3 / 16(18.75 \%)$ malignant peripheral nerve sheath tumor (Schwannoma, neurofibrosarcoma), 1/16 (6.25\%) hemangiosarcoma, 1/16 (6.25\%) histiocytic sarcoma, and 1/16 (6.25\%) osteosarcoma. Immunohistochemistry for S100 was necessary to adequately diagnose the $3 / 16(18.75 \%)$ malignant peripheral nerve sheath tumor, and safranin staining was required to diagnose $3 / 16(18.75 \%)$ samples, two of fibrosarcomas and one of osteosarcoma. Patients presented with fibrosarcomas had longer overall survival (median 545 days) than 
the ones presented with other histological subtypes (median 130.5 days) $[P=0.01]$ (Figure 1).

Regarding histologic grade, 10/16 (62.5\%) were classified as grade II; 4/16 (25\%) grade I, and 2/16 (12.5\%) grade III (Figure 2A \& 2B). Microvessel density ranged from 1.8 to 56.8 (mean $12.47 \pm 14.38$ ) neovessel per field (Figure 2C \& 2D). Histological grade and microvessel density were not correlated with overall survival.

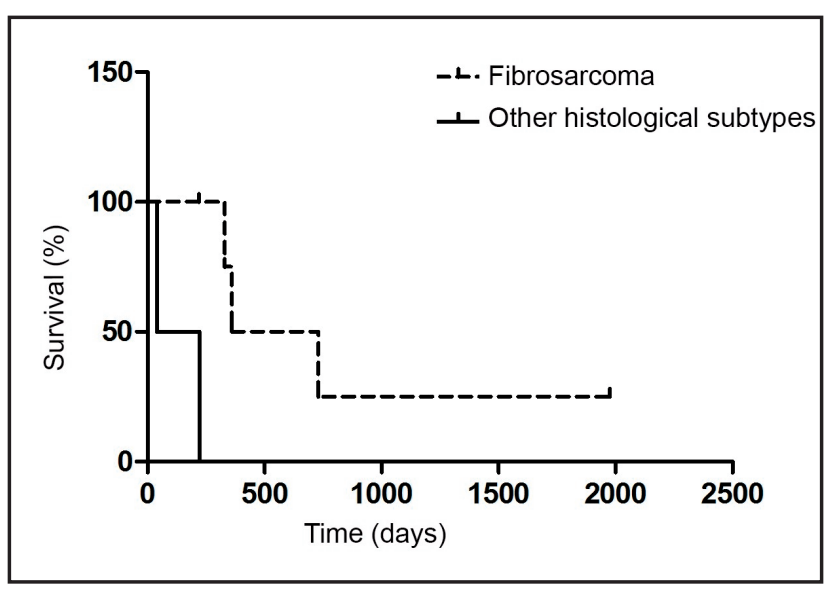

Figure 1. Overall survival curves for 16 cases of feline injection site associated sarcoma according to histological subtype. FISS characterized as fibrosarcomas presented longer overall survival (median 545 days) than other histological subtypes (median 130.5 days) $[P=0.01]$.

\section{Peritumoral inflammatory infiltrate}

Peritumoral inflammatory infiltrate was observed in all samples and classified as lymphocytic infiltrate in 11/16 (68.75\%) and lymphoplasmacytic in $5 / 16(31.25 \%)$ samples. The infiltrate intensity was low in $9 / 16(56.25 \%$ ) and moderate in $7 / 16(43.75 \%$ ) (Figure $3 \mathrm{~A} \& 3 \mathrm{~B})$. Distribution was considered multifocal in $13 / 16(81.25 \%)$, focal in $2 / 16(12.5 \%)$ and diffuse in $1 / 16(6.25 \%)$ cases. Inflammatory infiltrates organized under the form of lymphoid follicles were observed in two samples, both of grade III fibrosarcomas (Figure $3 \mathrm{C})$. There was a moderate and positive correlation $(P=0.005 ; \mathrm{r}=0.667)$ between tumor grade and lymphoid follicle formation. No correlation was observed between peritumoral infiltrate and lymphoid follicles with overall survival and Cox-2 or Ki-67 expression.

\section{Giant multinucleated cells}

Giant multinucleated cells were observed in only 4/16 (25\%) cases, all in grade II and III tumors (Figure 3D). While no statistically significant correlation was found, the presence of giant cells tended to prevail in tumors of higher histologic grade. Presence of giant multinucleated cells did not correlate with cellularity, Ki-67 and Cox-2 expression or overall survival. Necrosis was observed in 12/16 (75\%) cases, considered of moderate intensity in eight $(66.7 \%)$ and high intensity in four (33.3\%).

Cellularity and collagen production of fibrosarcomas were evaluated. Cellularity was considered moderate in $8 / 11(72.7 \%)$, high in $2 / 11(18.2 \%)$ and low in $1 / 11(9.1 \%)$ samples. Collagen production was considered high in $4 / 11(36.4 \%)$, moderate in $4 / 11$ $(36.4 \%)$ and low in $3 / 11(27.2 \%)$. Cellularity and collagen production of fibrosarcomas did not correlate with grade, microvessel density or overall survival.

\section{Cycloxygenase- 2 expression}

Cox-2 expression was observed in 13/16 (81.75\%) tumors and overexpression ( $\geq 50 \%$ positive cells) was observed in 3/16 (18.75\%) samples. A positive and moderate correlation $(P=0.696 ; \mathrm{r}=0.003)$ was observed between cellularity and Cox-2 expression (Figure 4A \& 4B). No correlation was found between Cox-2 expression and vascularity, Ki-67 expression, or overall survival. Immunohistochemical analysis for Ki-67 demonstrated a mean staining of $2.39 \pm 2.48$ (Figure 4C \& 4D). Low mitotic index (lower than 9 mitosis) was noted in 11/16 (68.7\%) samples, and between 10 and 19 mitosis in 5/16 (31.3\%) cases. Correlation between Ki-67 expression and cellularity, vascularity or overall survival was not observed.

\section{DISCUSSION}

Mean tumor diameter of FISS described in the present study was similar to a previous report [10]. Patients with FISS generally present with larger nodules than those with sarcomas not associated to injections, suggesting a challenge for pet owners to note subcutaneous tumors in the interscapular region, in addition to the aggressive biological behavior of FISS [25]. The influence of size on prognosis remains controversial, as a previous study observed that size did not influence prognosis directly [32], while another observed a trend to a better prognosis for tumors smaller than 4 centimeters [28].

Patient selection for the present study initiated in 2001, when the Vaccine-Associated Feline Sarcoma Task Force (VAFSTF) recommendations to vaccinate cats in the limbs were already established [29]. In the United States of America, a fast change in the location of injection site sarcomas was observed from 1990 to 2006 [33]. However, most of the sarcomas in this study developed in areas contraindicated for injections in felines, which may suggest that the VAFSTF recommendations remain unpracticed by many veterinarians in our region. 


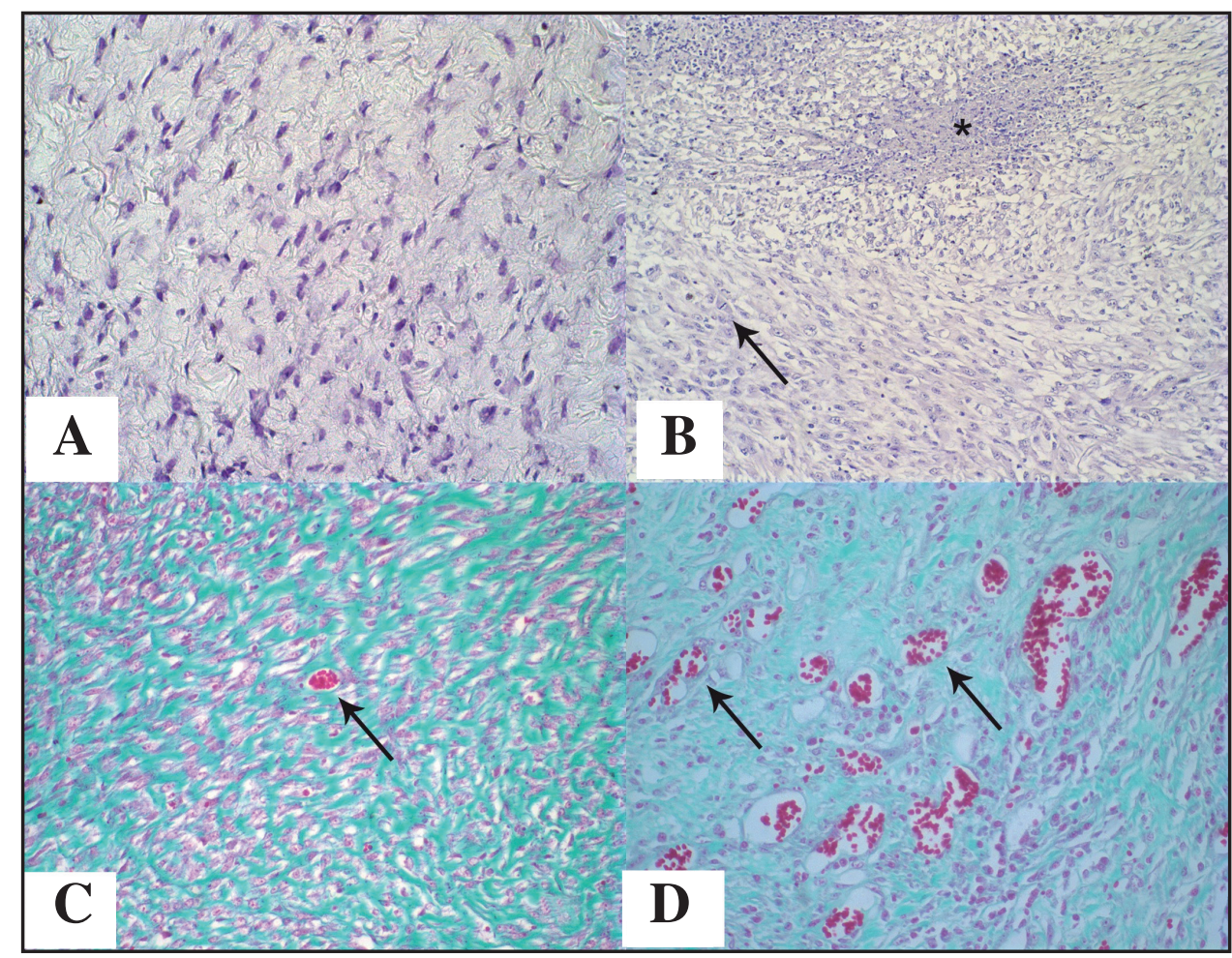

Figure 2. Feline Injection Site Sarcoma. A- Low histologic grade neoplasm presenting uniform cells without mitotic figures and necrosis [H\&E; $30 \mu \mathrm{m}]$; B- High histologic grade neoplasm revealing moderate cellular pleomorphism, mitotic figures (arrow), and necrosis (asterisk) [H\&E; $30 \mu \mathrm{m}]$. C- Neoplasia presenting low microvessel (arrow) density [Gomori Trichrome; $30 \mu \mathrm{m}$ ]. D- Neoplasia presenting high microvessel (arrows) density [Gomori Trichrome; $30 \mu \mathrm{m}]$.

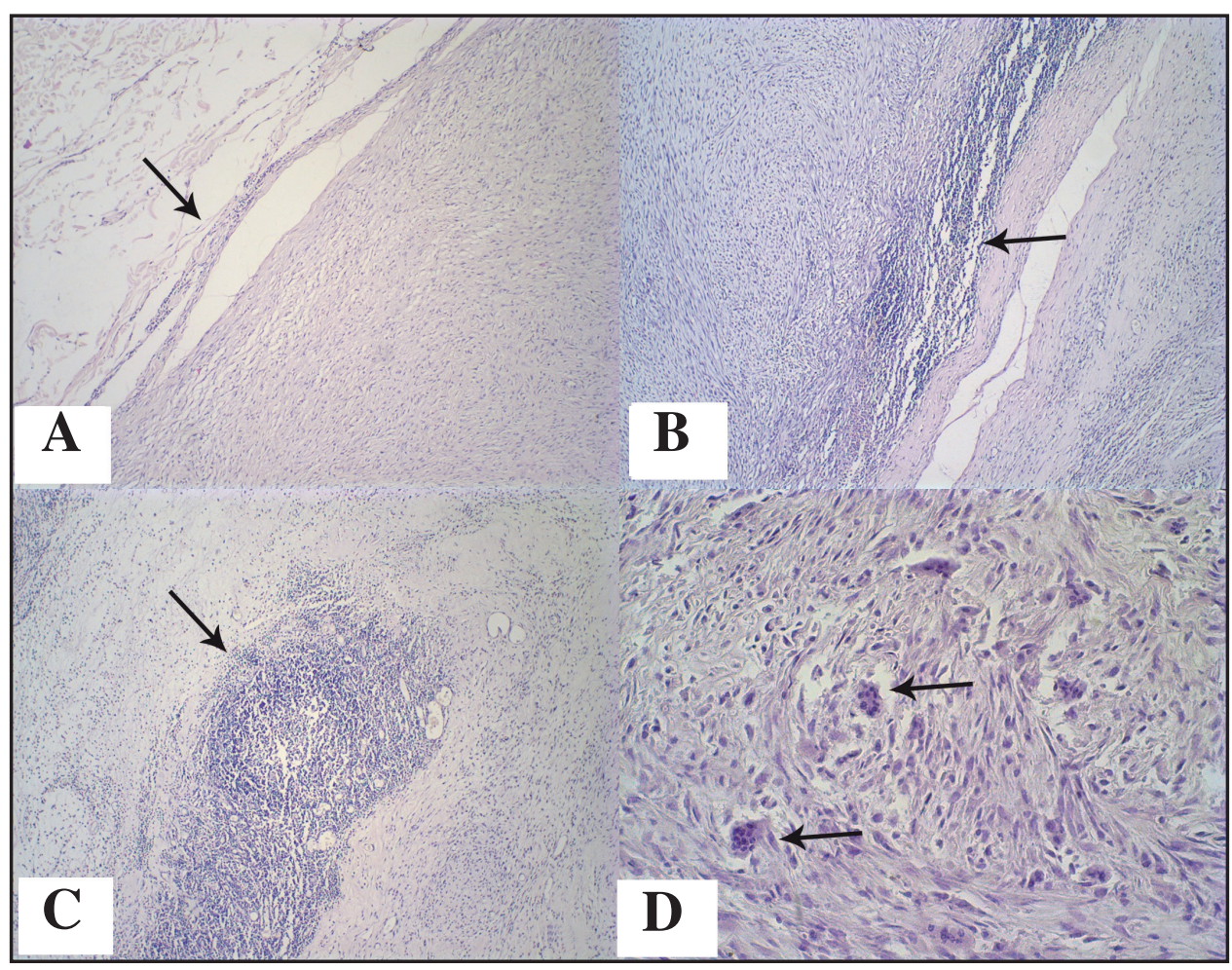

Figure 3. Feline Injection Site Sarcoma. A- Discrete peritumoral lymphocytic infiltrate (arrow) [H\&E; $50 \mu \mathrm{m}]$. BIntense peritumoral lymphocytic infiltrate (arrow) $[\mathrm{H \& E} ; 50 \mu \mathrm{m}]$. C- Peritumoral inflammatory infiltrate organized as a lymphoid follicle (arrow) [H\&E; $50 \mu \mathrm{m}]$. D- Giant multinucleated cells (arrow) [H\&E; $50 \mu \mathrm{m}]$. 


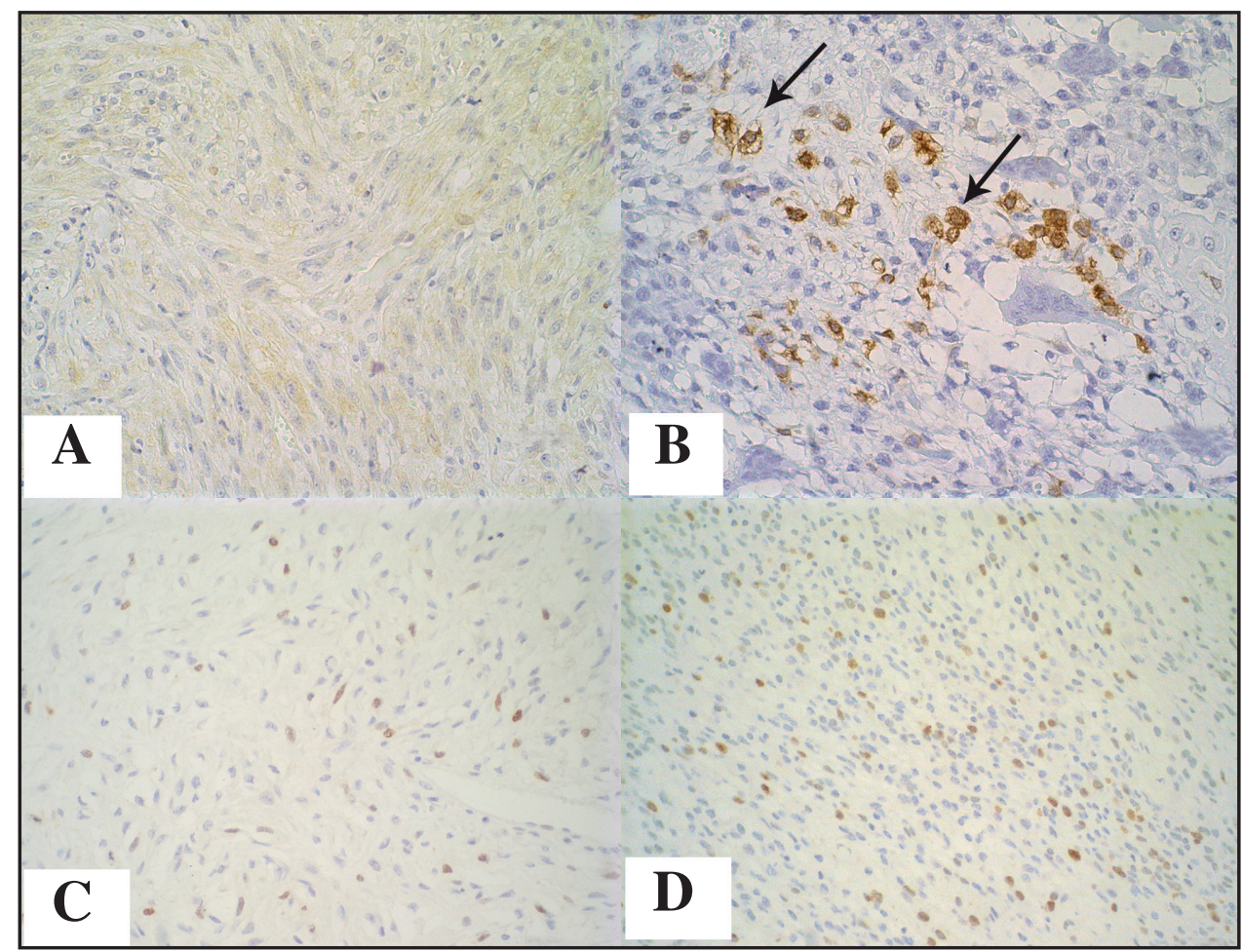

Figure 4. Feline Injection Site Associated Sarcoma. A- Negative neoplastic cells for Cox-2 immunolabeling. Polymeric detection system anti-Cox-2 [counterstained with Harris's hematoxylin; $30 \mu \mathrm{m}$ ]. B- Neoplastic cells presenting high intensity of Cox-2 immunolabeling (arrows). Polymeric detection system anti-Cox-2 [counterstained with Harris's hematoxylin; $30 \mu \mathrm{m}$ ] C- Neoplasia presenting low proliferation index. Polymeric detection system anti-Ki-67 [counterstained with Harris's hematoxylin; $30 \mu \mathrm{m}$ ]. D- Neoplasia presenting high proliferation index. Polymeric detection system anti-Ki-67 [counterstained with Harris's hematoxylin; $30 \mu \mathrm{m}$ ].

Fibrosarcomas are malignant neoplasms that originate from fibroblasts and are described as the most common histologic type of FISS, occurring in approximately $80 \%$ of cases [34]. Fibrosarcomas are also reported as the most common malignant mesenchymal tumor in cats, representing 12 to $25 \%$ of all skin tumors [13]. Other histological variants of FISS include malignant fibrous histiocytoma, osteosarcoma, chondrosarcoma, rhabdomyosarcoma, myxosarcoma, and undifferentiated sarcoma $[8,15]$. In addition, the present study reported, for the first time in the reviewed literature, the histological diagnosis of malignant peripheral nerve sheath tumor in FISS. An incidence of $3.2 \%$ of malignant peripheral nerve sheath tumor was reported in feline sarcomas, however no association to injection of vaccines or drugs administrations were described [31]. It is suggested that sarcomas observed in injection sites in felines should be classified histologically only as FISS, due to high pleomorphism [5]. A previous study did not observe association between histological diagnosis and prognosis in FISS [34]. However, in the present study, FISS fibrosarcomas presented a longer overall survival than other histological subtypes, demonstrating the importance of histopathological evaluation in the prognosis of FISS.

Histologic grade is the most important prognostic factor for soft tissue sarcomas in adult humans regarding distant metastasis probability and survival [22]. In FISS, retrospective studies did not find a correlation between histologic grade and recurrence [6,11] and overall survival [6]. An association between histologic grade and the development of metastasis has been observed, with patients with grade III FISS associated with an increase in the metastatic rate [32]. The present study did not find a correlation between overall survival and histologic grade.

Vascularization of FISS through immunohistochemical expression of factor VIII and observed staining has been reported in $0.3 \%$ to $4.8 \%$ of 
cells [5]. The different methodologies adopted for microvessel analysis precludes direct comparison of results. Although in both studies no correlation between microvessel density and histologic grade was observed.

Peritumoral inflammatory infiltrate was observed in all samples, corroborating with a previous study [5], that also identified a lymphocytic inflammatory infiltrate in the periphery of all FISS evaluated. It is hypothesized that myofibroblasts activated by the tumor form a protective capsule, mechanically preventing the penetration of T lymphocytes and macrophages into the tumor [5].

Our findings suggest a positive moderate correlation between histologic grade and lymphoid follicle formation amid inflammatory infiltrates. Several authors described the occurrence of perivascular lymphoid aggregates, without any correlation with tumor differentiation or progression $[5,8,30]$.

The absence of giant cells in grade I FISS corroborates with previous findings [10]. A positive correlation between the presence of giant multinucleated cells and tumor grade has been observed [5]. Despite the absence of such correlation in the present study, possibly due to a small sample, a trend for higher frequency of giant cells in advanced histologic grade was observed. In humans diagnosed with soft tissue sarcomas, the presence of giant intratumoral cells is correlated with aggressive and invasive phenotype and is important for prognosis [21].

Cox-2 expression in $81.75 \%$ and overexpression in $18.75 \%$ of our samples contrasts with the $64 \%$ Cox -2 expression [3] and the absence of Cox-2 expression found by other authors [1]. A positive moderate correlation between cellularity and Cox-2 expression was also observed, while another study did not find a correlation of Cox2 expression with tumor grade, recurrence rates or overall survival [3]. Cox metabolites such as prostaglandins can enhance cellular proliferation, inhibit apoptosis, induce angiogenesis, alter cellular adherence to facilitate metastatic development and inhibit immune surveillance [7]. In the present study, no correlation was found between Cox-2 and angiogenesis in FISS.

Our findings demonstrated low immunolabeling for Ki-67. A previous study analyzed 52 samples of FISS, $51 \%$ of them considered grade
III, with a mean Ki-67 labeling of 14\% [10]. The lower Ki-67 staining in the samples of the present study may be related to the lower number of samples of grade III FISS or to a difference in the studied population. Some authors did not observe meaningful differences in Ki-67 expression in varied grades of FISS [5,10], and it is also related an absence of correlation between Ki-67 expression and overall survival in felines with injection sarcoma [10]. Ki67 is considered an independent prognostic marker in high grade sarcomas of several histological subtypes that affect humans, related to disease-free and metastasis-free survival [20].

The mitotic index was considered low in most samples of FISS in this study, while most studies describe a high mitotic activity for this tumor $[5,8,15]$. The low mitotic index and the low Ki-67 expression in FISS can explain the low metastatic index of this tumor $[2,19]$ and the inconsistent answer to chemotherapy and radiotherapy $[4,10,24]$. Therefore, the aggressive behavior of FISS may not be related to rapid tumor proliferation, but to its local invasiveness, hindering surgical excision with clean margins, even with aggressive surgical interventions. The locally invasive behavior can also be related to the recurrence of up to $42 \%$ of FISS in which margins were considered clean [24].

\section{CONCLUSION}

Characterization of the histological subtype of FISS is essential, since fibrosarcomas are associated with a better prognosis when compared to other histological subtypes. Biological behavior of FISS does not seem to be related to its proliferation index or Cox-2 expression. More undifferentiated neoplasms are associated with peritumoral inflammatory infiltrate organized under lymphoid follicles. Furthermore, malignant peripheral nerve sheath tumors were diagnosed as a possible histological subtype of FISS.

\section{MANUFACTURERS}

${ }^{1}$ Thermo Fisher Scientific Inc. Waltham, MA, USA.

${ }^{2}$ Sigma-Aldrich Brasil. São Paulo, SP, Brazil.

${ }^{3}$ DakoCytomation A.S. Glostrup, Denmark.

Declaration of interest. The authors declared no potential conflicts of interest with respect to the research, authorship, and/or publication of this article 


\section{REFERENCES}

1 Beam S.L., Rassnick K.M., Moore A.S. \& McDonough S.P. 2003. An immunohistochemical study of cyclooxygenase-2 expression in various feline neoplasms. Veterinary Pathology. 40: 496-500.

2 Burton G. \& Mason K.V. 1997. Do post vaccinal sarcomas occur in Australian cats? Australian Veterinary Journal. 75: 102-106.

3 Carneiro C.S. 2012. Caracterização dos pacientes portadores de sarcoma de aplicação felino quanto ao escore de condição corporal, à origem de sua formação e ao microambiente de seu desenvolvimento. 120f. São Paulo, SP. PhD Thesis, Universidade de São Paulo, Brazil.

4 Cohen M., Wright J.C., Brawner W.R., Smith A.N., Henderson R. \& Behrend E.N. 2001. Use of a surgery and electron beam irradiation, with or without chemotherapy, for treatment of vaccine-associated sarcomas in cats: 78 cases (1996-2000). Journal of the American Veterinary Medical Association. 219: 1582-1589.

5 Couto S.S., Griffey S.M., Duarte P.C. \& Madewell B.R. 2002. Feline vaccine-associated fibrosarcoma: morphologic distinctions. Veterinary Pathology. 39: 33-41.

6 Davidson E.B., Gregory C.R. \& Kass P.H. 1997. Surgical excision of soft tissue fibrosarcomas in cats. Veterinary Surgery. 26: 265-269.

7 Dempke W., Rie C., Grothey A. \& Schmoll H.J. 2001. Cyclooxygenase-2: a novel target for cancer chemotherapy? Journal of Cancer Research and Clinical Oncology. 127: 411-417.

8 Doddy F.D., Glickman L.T., Glickman N.W. \& Janovitz E.B. 1996. Feline fibrosarcomas at vaccination sites and non-vaccination sites. Journal of Comparative Pathology. 114: 165-174.

9 Dutra A.P., Granja N.V.M., Schmitt F.C \& Cassali G.D. 2004. C-erbB-2 expression and nuclear pleomorphism in canine mammary 98 tumors. Brazilian Journal of Medical and Biological Research. 37: 1673-1681.

10 Eckstein C., Guscetti F., Roos M., Martín de las Mulas J., Kaser-Hotz B., Rohrer Bley C. 2009. A retrospective analysis of radiation therapy for the treatment of feline vaccine-associated sarcoma. Veterinary Comparative Oncology. 7: 54-68.

11 Giudice C., Stefanello D., Sala M., Cantatore M., Russo F., Romussi S., Travetti O., Di Giancamillo M. \& Grieco V. 2010. Feline injection-site sarcoma: Recurrence, tumor grading and surgical margin status evaluated using the threedimensional histological technique. Veterinary Journal. 186: 84-88.

12 Gober G.M. \& Kass P.H. 2002. World Wide Web-Based Survey of vaccination practices, post vaccination reactions, and vaccine-site associated sarcomas in cats. Journal of the American Veterinary Medical Association. 220: 1477-1482.

13 Gross T.L., Ihrke P.J. \& Walder E. 1992. Veterinary Dermatopathology: A Macroscopic and Microscopic Evaluation of Canine and Feline Skin Disease. St Louis: Mosby-Year Book, 484p.

14 Hazozaki M., Tajino T., Konno S., Kikuchi S., Yamada H., Yanagisawa M., Nishida J., Nagasawa H., Tsuchiya T., Ogose A., Abe M. \& Hojo H. 2014. Overexpression of Cyclooxygenase-2 in Malignant Peripheral Nerve Sheath Tumor and Selective Cyclooxygenase-2 Inhibitor-Induced Apoptosis by Activating Caspases in Human Malignant Peripheral Nerve Sheath Tumor Cells. Plos One. 9: 1-10.

15 Hendrick M.J. \& Brooks J.J. 1994. Postvaccinal sarcomas in the cat: Histology and immunohistochemistry. Veterinary Pathology. 31: 126-129.

16 Hendrick M.J. \& Goldschmidt M.H. 1991. Do injection site reactions induce fibrosarcomas in cats? (letter). Journal of American Veterinary Medical Association. 199: 968.

17 Hendrick M.J., Mahaffrey E.A. \& Moore F.M. 1998. Histological classification of mesenchymal tumors of skin and soft tissues of domestic animals. World Health Organization International Histological Classification of Tumors of Domestic Animals. Washington DC: The Armed Forces Institute of Pathology, 64p.

18 Hendrick M.J., Shofer F.S., Goldschmidt M.H., Haviland J.C., Schelling S.H., Engler S.J. \& Gliatto J.M. 1994. Comparison of fibrosarcomas that developed at vaccination sites and at nonvaccination sites in cats: 239 cases (19911992). Journal of American Veterinary Medical Association. 205: 1425-1429.

19 Hershey A.E., Sorenmo K.U., Hendrick M.J., Shofer F.S. \& Vail D.M. 2000. Prognosis for presumed feline vaccineassociated sarcoma after excision: 61 cases (1986-1996). Journal of the American Veterinary Medical Association. 216 : 58-61.

20 Heslin M.J., Cordon-Cardo C., Lewis J.J., Woodruff J.M. \& Brennan M.F. 1998. Ki-67 detected by MIB-1 predicts distant metastasis and tumor mortality in primary, high grade extremity soft tissue sarcoma. Cancer. 83: 490-497. 
21 Jöston M. \& Rudolph R. 1997. Methods for the differentiation of giant cells in canine and feline neoplasia in paraffin sections. Journal of Veterinary Medical Sciences. 44: 159-166.

22 Kandel R.A., Bell R.S., Wunder J.S., O’Sullivan B., Catton C.N., White L.M. \& Davis A.M. 1999. Comparison between a 2- and a 3-grade system in predicting metastatic-free survival in extremity soft tissue sarcoma. Journal of Surgical Oncology. 72: 77-82.

23 Kass P.H., Barnes Jr. W.G., Spangler W.L., Chomel B.B \& Culbertson M.R. 1993. Epidemiologic evidence for a causal relation between vaccination and fibrosarcoma tumorigenesis in cats. Journal of the American Veterinary Association. 203: 396-405.

24 Kobayachi T., Hauck M.L., Dodge R., Page R.L., Sylvester Price G., Williams L.E., Hardie E.M., Mathews K.G. \& Thrall D.E. 2002. Preoperative radiotherapy for vaccine associated sarcoma in 92 cats. Veterinary Radiology \& Ultrasound. 43: 473-479.

25 Ladlow J. 2013. Injection-Site Associated Sarcoma in the Cat: Treatment Recommendations and Results to Date. Journal of Feline Medicine and Surgery. 15: 409-418.

26 Lester S., Clemett T. \& Burt A. 1996. Vaccine site-associated sarcomas in cats: clinical experience and a laboratory review (1982 - 1993). Journal of the American Veterinary Medical Association. 32: 91-95.

27 Liptak J.M. \& Forrest L.J. 2013. Soft Tissue Sarcomas. In: Withrow S.J. \& MacEwen D.V. (Eds). Small Animal Clinical Oncology. 5th edn. St. Louis: Saunders, pp.356-380.

28 Martano M., Morello E., Ughetto M., Iussich S., Petterino C., Cascio P. \& Buracco P. 2005. Surgery alone versus surgery and doxorubicin for the treatment of feline injection-site sarcomas: a report on 69 cases. Veterinary Journal. 170: 84-90.

29 Morrison W.B. \& Starr R.M. 2001. Vaccine-associated feline sarcoma task force. Vaccine-associated feline sarcomas. Journal of the American Veterinary Medical Association. 218: 697-702.

30 Nieto A., Sánchez M.A, Martínez E. \& Rollán E. 2003. Immunohistochemical expression of p53, fibroblast growth factor-b, and transforming growth factor- $\alpha$ in feline vaccine-associated sarcomas. Veterinary Pathology. 40: 651-658.

31 Ochôa C. \& Lopes C. 2008. Contributo para a caracterização dos sarcomas dos tecidos moles do gato e identificação de factores de prognóstico. Revista Portuguesa de Ciências Veterinárias. 103: 5-15.

32 Romanelli G., Marconato L., Olivero D., Massari F. \& Zini E. 2008. Analysis of prognostic factors associated with injection-site sarcoma in cats: 57 cases (2001 - 2007). Journal of the American Veterinary Medical Association. 232: 1193-1199.

33 Shaw S.C., Kent M.S., Gordon I.K., Collins C.J., Greasby T.A., Beckett L.A, Hammond G.M. \& Skorupski K.A. 2009. Temporal changes in characteristics of injection-site sarcomas in cats: 392 cases (1990 - 2006). Journal of the American Animal Hospital Association. 234: 376-380.

34 Wilcock B., Wilcock A. \& Bottoms K. 2012. Feline Postvaccinal Sarcoma: 20 years later (Brief Communication). Canadian Veterinary Journal. 53: 430-434. 